\title{
Tricetin Protects Rat Chondrocytes against IL-1 $\beta$-Induced Inflammation and Apoptosis
}

\author{
Fang-Fang Sun $\mathbb{D}^{1},{ }^{1}$ Peng-Fei Hu $\mathbb{D}^{2,3}$ Yan Xiong, ${ }^{2,3}$ Jia-Peng Bao, ${ }^{2,3}$ Jing Qian $\mathbb{D}^{4},{ }^{4}$ \\ and Li-Dong $W u\left(\mathbb{D}^{2,3}\right.$
}

${ }^{1}$ Key Laboratory of Cancer Prevention and Intervention, China National Ministry of Education, The Second Affiliated Hospital,
Cancer Institute, School of Medicine, Zhejiang University, Hangzhou, Zhejiang 310009, China
${ }^{2}$ Department of Orthopedic Surgery, The Second Affiliated Hospital, School of Medicine, Zhejiang University, Hangzhou,
Zhejiang 310009, China
${ }^{3}$ Orthopedics Research Institute of Zhejiang University, Hangzhou, Zhejiang 310009, China
${ }^{4}$ Pharmaceutical Informatics Institute, College of Pharmaceutical Sciences, Zhejiang University, Hangzhou, Zhejiang 310058, China

Correspondence should be addressed to Jing Qian; jingqian@zju.edu.cn and Li-Dong Wu; wulidong@zju.edu.cn

Fang-Fang Sun and Peng-Fei Hu contributed equally to this work.

Received 30 January 2019; Revised 30 March 2019; Accepted 9 April 2019; Published 28 April 2019

Academic Editor: Sonia de Pascual-Teresa

Copyright (C) 2019 Fang-Fang Sun et al. This is an open access article distributed under the Creative Commons Attribution License, which permits unrestricted use, distribution, and reproduction in any medium, provided the original work is properly cited.

Tricetin is a well-studied flavonoid with a wide range of pharmacological activities in cancer and inflammation. However, the ability of tricetin to ameliorate the inflammation that occurs in osteoarthritis (OA) has not been determined. This study explored the effects of tricetin on interleukin- (IL-) $1 \beta$-induced rat chondrocytes. Chondrocytes harvested from rat cartilage were incubated in vitro with tricetin in the presence of IL- $1 \beta$. The expression of matrix metalloproteinase- (MMP-) 1, MMP-3, MMP-13, nitric oxide (NO), prostaglandin E2 (PGE2), Bax, and Bcl-2 was evaluated by real-time-PCR, ELISA, Griess reaction, and western blotting. Caspase-3 activity in chondrocytes was determined using a caspase-3 activity assay and MAPK pathway activity by western blotting. Tricetin decreased the expression of MMP-1, MMP-3, and MMP-13 at both the gene and protein level in IL- $1 \beta$-induced rat chondrocytes. It also inhibited IL- $1 \beta$-induced NO and PGE2 production, by modulating inducible NO synthase and cyclooxygenase 2 gene expression. An antiapoptotic role of tricetin involving the Bax/Bcl-2/caspase-3 pathway was also determined. The chondroprotective effect of tricetin was shown to be partly related to the suppression of the MAPK signaling pathway. The results of this study demonstrate the chondroprotective role of tricetin, based on its anticatabolic, anti-inflammatory, and antiapoptotic effects in chondrocytes. The therapeutic potential of tricetin in OA patients should be explored in future studies.

\section{Introduction}

As the average age of populations throughout the world is steadily rising, osteoarthritis (OA) has become an increasingly large economic burden in many countries [1]. OA is a chronic, degenerative joint disease that causes substantial pain and functional disability. Inflammation of the joint tissue, degradation of the extracellular matrix (ECM), oxidative stress, and chondrocyte apoptosis all contribute substantially to the pathogenesis of OA $[2,3]$. In OA, the activities of catabolic factors, such as matrix metalloproteinases (MMPs) and a disintegrin and metalloproteinase with thrombospondin motifs (ADAMTS), as well as of inflammatory cytokines, such as interleukin- (IL-) $1 \beta$, IL-6, and tumor necrosis factor- (TNF-) $\alpha$, result in cartilage erosion and bone damage $[4,5]$. Chondrocytes are the only resident cells in the articular cartilage, and they contribute to maintaining cartilage metabolism. Although the primary cause of OA is still not fully understood, the apoptosis of chondrocytes has been shown to play an essential role in disease initiation. Specifically, in the previous study, the percentage of apoptotic chondrocytes was higher in cartilage samples obtained from OA patients than in normal cartilage (18-21\% vs. $2-5 \%$ ) [6]. Articular cartilage is avascular, with no cell turnover, and 
the degree of articular erosion is positively associated with chondrocyte apoptosis [7]. Given the complexity of the pathophysiology of OA, very few effective disease-modifying drugs are currently available for clinical use, and the search for new drugs able to prevent OA progression continues.

In recent years, the therapeutic potential of natural plant products has received increasing attention. Flavonoids, a large class of polyphenolic plant compounds, are present in fruit, vegetables, chocolate, and beverages and can be easily extracted from these products [8]. Moreover, several studies have reported the anti-inflammatory, antithrombogenic, antidiabetic, anticancer, and neuroprotective activities of flavonoids via diverse mechanisms of action [9-13]. There is also evidence of a therapeutic effect of flavonoids in OA. Chen et al. reported that licochalcone A, a classical flavonoid separated from licorice, inhibits the expression of MMP-1, MMP-13, ADAMTS4, and ADAMTS5 in IL- $1 \beta$-induced chondrocytes, by regulating the NF- $\kappa \mathrm{B}$ and wnt $/ \beta$-catenin signaling pathways [14]. Chondroprotective effects were also reported for the flavonoid silibinin [15], in a study showing that it significantly decreased the IL- $1 \beta$-induced expression of proinflammatory mediators and MMPs in human OA chondrocytes. The present study investigated the flavonoid tricetin $\left(5,7,3^{\prime}, 4^{\prime}, 5^{\prime}\right.$-pentahydroxyflavone), obtained from Myrtaceae pollen and eucalyptus honey [16]. The many biological actions of tricetin include anticancer and anti-inflammatory activities [17, 18]. However, whether tricetin is effective in treating OA has not been investigated. Thus, using rat chondrocytes, we examined the pharmaceutical role of tricetin in the treatment of OA by determining the expression of inflammatory and apoptotic mediators in chondrocytes pretreated with tricetin. The mechanisms underlying the observed actions of tricetin in this OA model were also explored.

\section{Materials and Methods}

2.1. Reagents. Tricetin (purity $\geq 99 \%$ ) was obtained from Extrasynthese, Genay, France. Recombinant rat IL- $1 \beta$, MTT, and type II collagenase were purchased from SigmaAldrich, Merck KGaA, Darmstadt, Germany. Dulbecco's Modified Eagle's Medium (DMEM), penicillin, streptomycin, fetal calf serum (FBS), 0.25\% pancreatic enzyme, TRIzol reagent, and cDNA synthesis kit were all purchased from Thermo Fisher Scientific Inc. PGE2 ELISA kit was purchased from R\&D Systems, Minneapolis, MN, USA. Caspase-3 cellular activity assay kit, cell lysis buffer, and antibodies against ERK1/2, p-ERK1/2, p38, p-p38, JNK, and p-JNK were purchased from Cell Signaling Technology, Danvers, MA, USA. Antibodies against MMP-3, MMP-13, Bcl-2, and Bax were purchased from Abcam, Cambridge, USA. Antibody against MMP-1 was purchased from Proteintech Group Inc., Rosemont, USA. Griess reagent was purchased from Beyotime, Shanghai, China. SYBR Premix Ex Taq II was purchased from Takara Biotechnology, Dalian, China.

2.2. Cell Culture and Treatment. The study was approved by the Ethics Committee of the Second Affiliated Hospital, Zhejiang University School of Medicine, Hangzhou, China (2019-01). Cartilage pieces obtained from the hip and knee

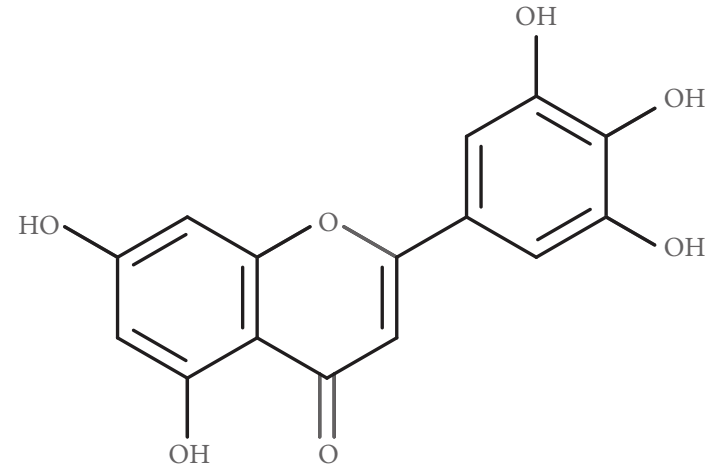

Figure 1: Chemical structure of tricetin.

joints of 6-week-old Sprague-Dawley (SD) rats (24 rats; sex ratio: $1: 1$ ) were digested with $0.25 \%$ pancreatic enzyme for $30 \mathrm{~min}$, followed by $0.2 \%$ collagenase II for $2 \mathrm{~h}$. The chondrocytes collected from the digest were cultured as a monolayer in DMEM supplemented with $10 \%$ fetal calf serum, penicillin $(100 \mathrm{U} / \mathrm{ml})$ and streptomycin $(100 \mathrm{~g} / \mathrm{ml})$ at $37^{\circ} \mathrm{C}$ in an atmosphere of $5 \% \mathrm{CO}_{2}$.

2.3. Cell Viability Assay. The cytotoxicity of tricetin in the chondrocyte cultures was determined in an MTT assay, conducted to select a nontoxic concentration range for use in the subsequent experiments. The assay was performed according to the manufacturer's instructions. Chondrocytes $\left(5 \times 10^{3}\right.$ cells/well) seeded in 96-well plates were incubated with various concentrations of tricetin (Figure 1) for $24 \mathrm{~h}$ at $37^{\circ} \mathrm{C}$ and then with $20 \mu \mathrm{l} \mathrm{MTT}(5 \mathrm{mg} / \mathrm{ml})$ for $4 \mathrm{~h}$ at $37^{\circ} \mathrm{C}$. The resulting MTT formazan crystals were solubilized with an equal volume of dimethyl sulfoxide (DMSO). The absorbance of the contents of each well was measured at $570 \mathrm{~nm}$ using a microplate reader. Concentrations that did not result in a significantly toxic effect were selected for further use in the experiments.

2.4. Quantitative Real-Time Polymerase Chain Reaction ( $q R T-P C R)$. The rats were divided into four groups: control, IL- $1 \beta$, IL- $1 \beta+$ low-dose $(10 \mu \mathrm{m})$ tricetin, and IL- $\beta+$ highdose $(20 \mu \mathrm{M})$ tricetin. Chondrocytes $\left(5 \times 10^{5}\right.$ cells/well $)$ were seeded in 6-well plates and stimulated or not with tricetin for $3 \mathrm{~h}$. IL-1 $\beta$ (10 $\mathrm{ng} / \mathrm{ml})$ was then added to the wells of all groups except for the control. After $24 \mathrm{~h}$ of incubation. The cultures were assayed by real-time PCR (RT-PCR) for the expression of MMP-1, MMP-3, MMP-13, inducible NO synthase (iNOS), cyclooxygenase 2 (COX-2), Bcl-2, and Bax. Total RNA was extracted from all four groups using the TRIzol reagent according to the manufacturer's instructions, and 1 $\mu \mathrm{g}$ RNA was reverse transcribed using the cDNA synthesis kit. RT-PCR was performed using the SYBR Premix Ex Taq II system as follows: 45 cycles of $95^{\circ} \mathrm{C}$ for $15 \mathrm{~s}$ and $60^{\circ} \mathrm{C}$ for $30 \mathrm{~s}$. The sequences of the primers used in the reaction are listed in Table 1. Relative gene expression was calculated using the $2^{-\Delta \Delta C t}$ method. GAPDH served as the internal control gene.

2.5. ELISA and the Griess Reaction. Cell culture supernatants were assayed for prostaglandin E2 (PGE2) expression using 
TABLE 1: Real-time PCR primers and conditions.

\begin{tabular}{|c|c|c|c|c|}
\hline Gene & GenBank accession & Primer sequences $\left(5^{\prime}\right.$ to $\left.3^{\prime}\right)$ & Size (bp) & Annealing $\left({ }^{\circ} \mathrm{C}\right)$ \\
\hline \multirow{2}{*}{ GAPDH } & \multirow{2}{*}{ NM_017008.4 } & GAAGGTCGGTGTGAACGGATTTG & \multirow{2}{*}{127} & \multirow{2}{*}{60} \\
\hline & & CATGTAGACCATGTAGTTGAGGTCA & & \\
\hline \multirow{2}{*}{ MMP-1 } & \multirow{2}{*}{ NM_001134530.1 } & GCTTAGCCTTCCTTTGCTGTTGC & \multirow{2}{*}{136} & \multirow{2}{*}{60} \\
\hline & & GACGTCTTCACCCAAGTTGTAGTAG & & \\
\hline \multirow{2}{*}{ MMP-3 } & \multirow{2}{*}{ NM_133523 } & CTGGGCTATCCGAGGTCATG & \multirow{2}{*}{77} & \multirow{2}{*}{60} \\
\hline & & TGGACGGTTTCAGGGAGGC & & \\
\hline \multirow{2}{*}{ MMP-13 } & \multirow{2}{*}{ NM_133530 } & CAACCCTGTTTACCTACCCACTTAT & \multirow{2}{*}{85} & \multirow{2}{*}{60} \\
\hline & & CTATGTCTGCCTTAGCTCCTGTC & & \\
\hline \multirow{2}{*}{ COX-2 } & \multirow{2}{*}{ S67722 } & CGCATTCTTTGCCCAGCACTTCACT & \multirow{2}{*}{190} & \multirow{2}{*}{60} \\
\hline & & CACCTCTCCACCGATGACCTGATA & & \\
\hline \multirow{2}{*}{ iNOS } & \multirow{2}{*}{ NM_012611.3 } & GCTCGGGCTGAAGTGGTATGC & \multirow{2}{*}{127} & \multirow{2}{*}{60} \\
\hline & & GAAGTCTCGGACTCCAATCTCGGT & & \\
\hline \multirow{2}{*}{$\mathrm{Bcl} 2$} & \multirow{2}{*}{ L14680 } & GGCTACGAGTGGGATACTGGAGAT & \multirow{2}{*}{86} & \multirow{2}{*}{60} \\
\hline & & CTCTCAGGCTGGAAGGAGAAGATG & & \\
\hline \multirow{2}{*}{ Bax } & \multirow{2}{*}{ NM_017059 } & CCCCAGGACGCATCCACCAA & \multirow{2}{*}{112} & \multirow{2}{*}{60} \\
\hline & & GGGAGTCTGTATCCACATCAGCAA & & \\
\hline
\end{tabular}

an ELISA kit according to the manufacturer's instructions. All assays were performed in duplicate. Nitric oxide (NO) production was measured by quantifying the accumulation of nitrite, a stable end product, according to the Griess reaction, and performed as follows: $100 \mu \mathrm{l}$ of the culture medium was mixed with an equal volume of the Griess reagent $(1 \%$ sulfanilamide $/ 0.1 \%$ naphthylethyllene dihydrochloride $/ 2.5 \%$ phosphoric acid). After $15 \mathrm{~min}$ at room temperature, the absorbance of the reaction at $540 \mathrm{~nm}$ was determined. All assays were performed in duplicate.

2.6. Caspase-3 Activity. Chondrocytes $\left(5 \times 10^{4}\right.$ cells/well $)$ were seeded in 96-well plates and divided into four groups with the similar treatment. A caspase-3 cellular activity assay kit was used to determine caspase- 3 activity in the four groups. The reaction is based on the cleavage of the fluorogenic substrate (N-acetyl-Asp-Glu-Val-Asp-7-amido4-methylcoumarin: Ac-DEVDAMC) between the DEVD and AMC moieties by activated caspase-3. Highly fluorescent $\mathrm{AMC}$ is then detected at an excitation wavelength of $380 \mathrm{~nm}$ using a fluorescence reader. In this study, chondrocytes pretreated in the growth medium supplemented or not with low- and high-dose tricetin for $3 \mathrm{~h}$ were incubated or not with rat recombinant IL- $\beta(10 \mathrm{ng} / \mathrm{ml})$ for $24 \mathrm{~h}$. According to the manufacturer's protocol, the chondrocytes were collected and lysed in cell lysis buffer in the presence or absence of $5 \mu \mathrm{l}$ DEVD-pNA for $1 \mathrm{~h}$ at $37^{\circ} \mathrm{C}$. Caspase- 3 activity was measured at $405 \mathrm{~nm}$ on a microplate reader. The experiment was performed in triplicate.

2.7. Western Blotting. Chondrocytes $\left(2 \times 10^{6}\right.$ cells/well $)$ were seeded in 6-well plates and divided into four groups. In brief, chondrocytes were harvested and lysed with cell lysis buffer. The BCA protein assay kit was used to determine protein concentrations. For each sample, $20 \mu \mathrm{g}$ of protein was loaded and resolved by SDS-PAGE on a $10 \%$

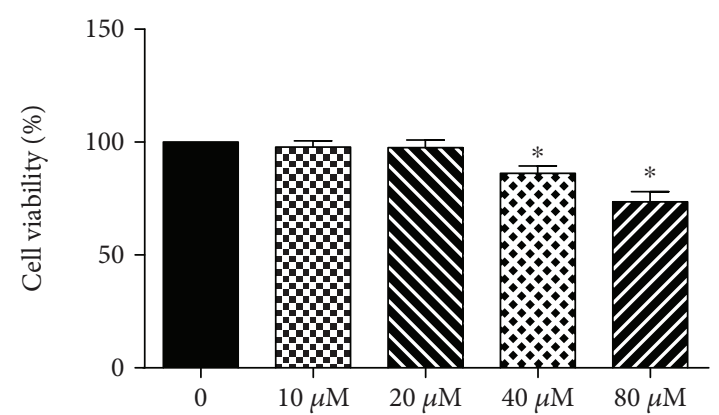

FIGURE 2: Effects of tricetin on cell viability as evaluated by MTT assay. Chondrocytes were treated with $10-80 \mu \mathrm{M}$ tricetin for $24 \mathrm{~h}$. Cells incubated in the medium without tricetin were used as the control, and their viability was set at $100 \%$. The values are expressed as mean $\pm \mathrm{SD}$ from triplicate samples in three independent experiments. ${ }^{*} p<0.05$ vs. the control group.

polyacrylamide gel. The proteins were transferred onto a nitrocellulose membrane and incubated overnight at $4{ }^{\circ} \mathrm{C}$ with primary antibodies against MMP-1, MMP-3, MMP13, Bcl-2, Bax, ERK1/2, p-ERK1/2, p38, p-p38, JNK, and $\mathrm{p}$-JNK. The membranes were then washed with TBS-T and incubated with secondary antibodies for $1 \mathrm{~h}$ at room temperature. Immunoreactive bands were detected using an enhanced chemiluminescence assay (Fude Biological Technology, Hangzhou, China) and exposed on Kodak XOmat film (Kodak, Rochester, NY, USA).

2.8. Statistical Analysis. The data are reported as mean \pm standard deviation (SD). All experiments were performed at least three times. A one-way analysis of variance and post hoc Tukey's test were performed using SPSS (ver. 19.0; IBM Corp., Armonk, NY, USA) and GraphPad Prism 7 (GraphPad Software Inc., La Jolla, CA, USA) software. For 

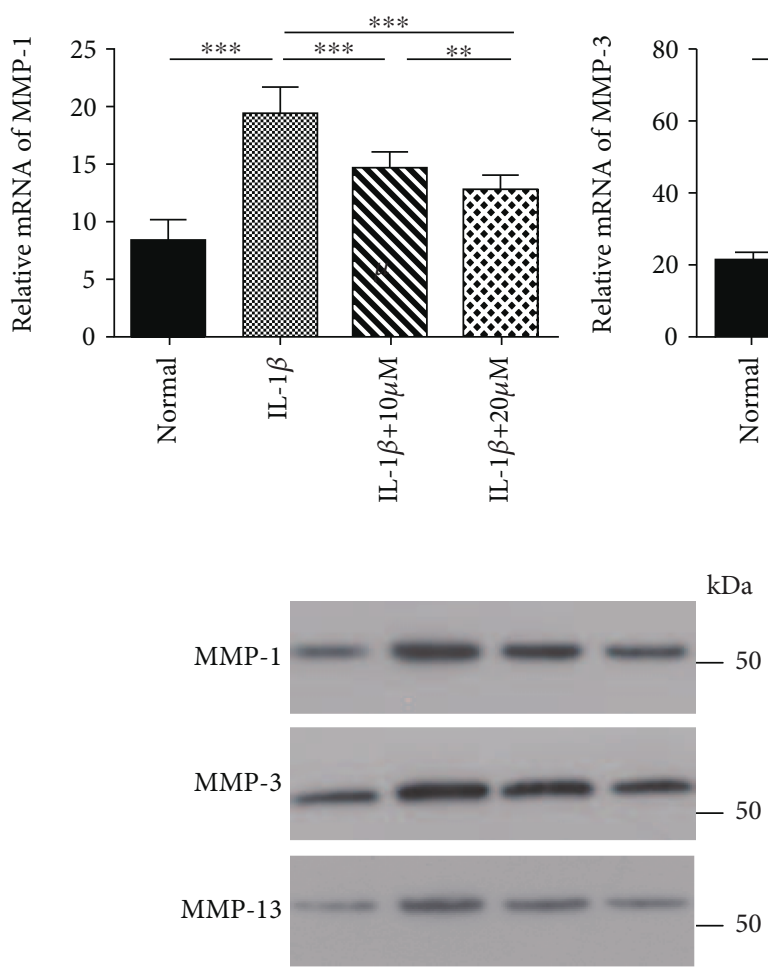

GAPDH

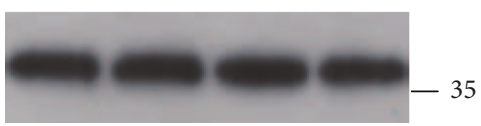

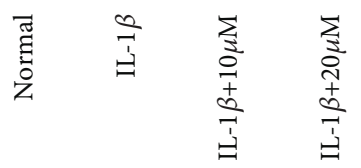

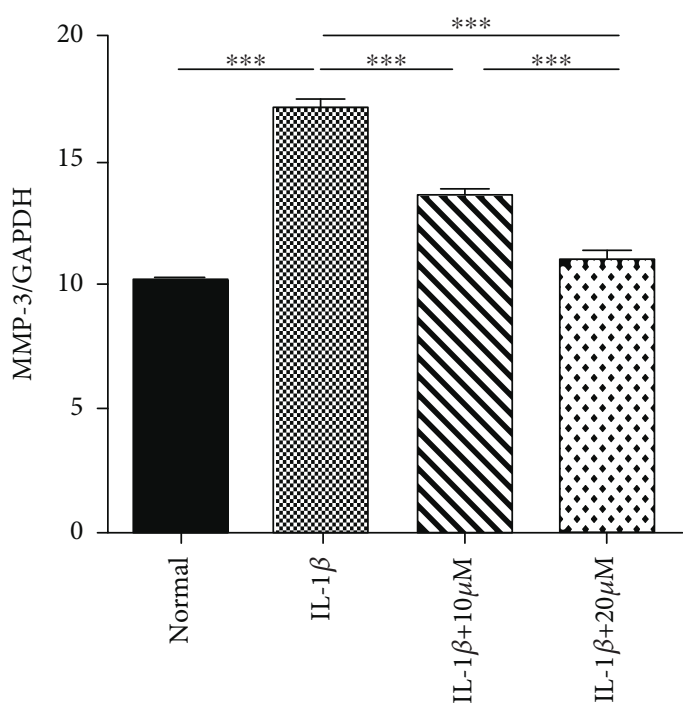

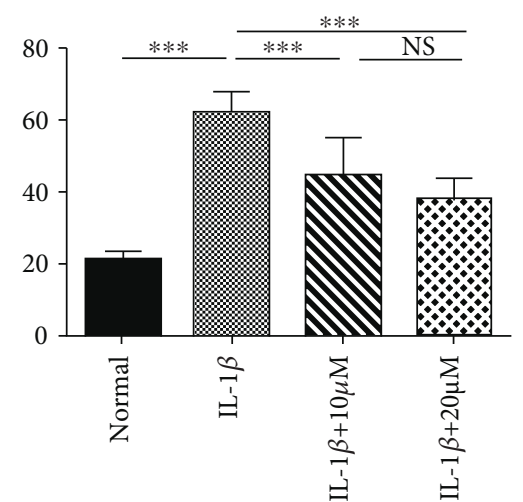

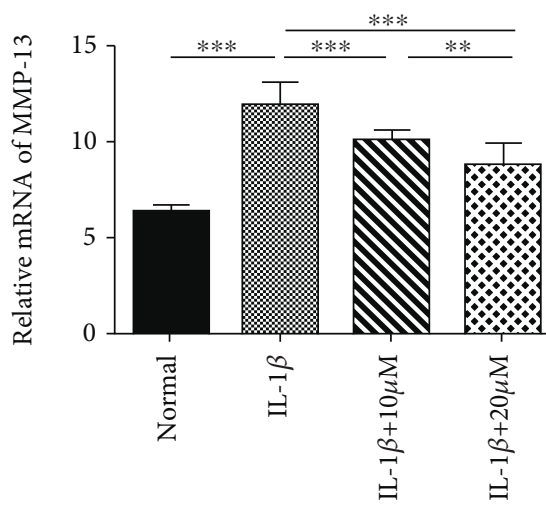

(a)
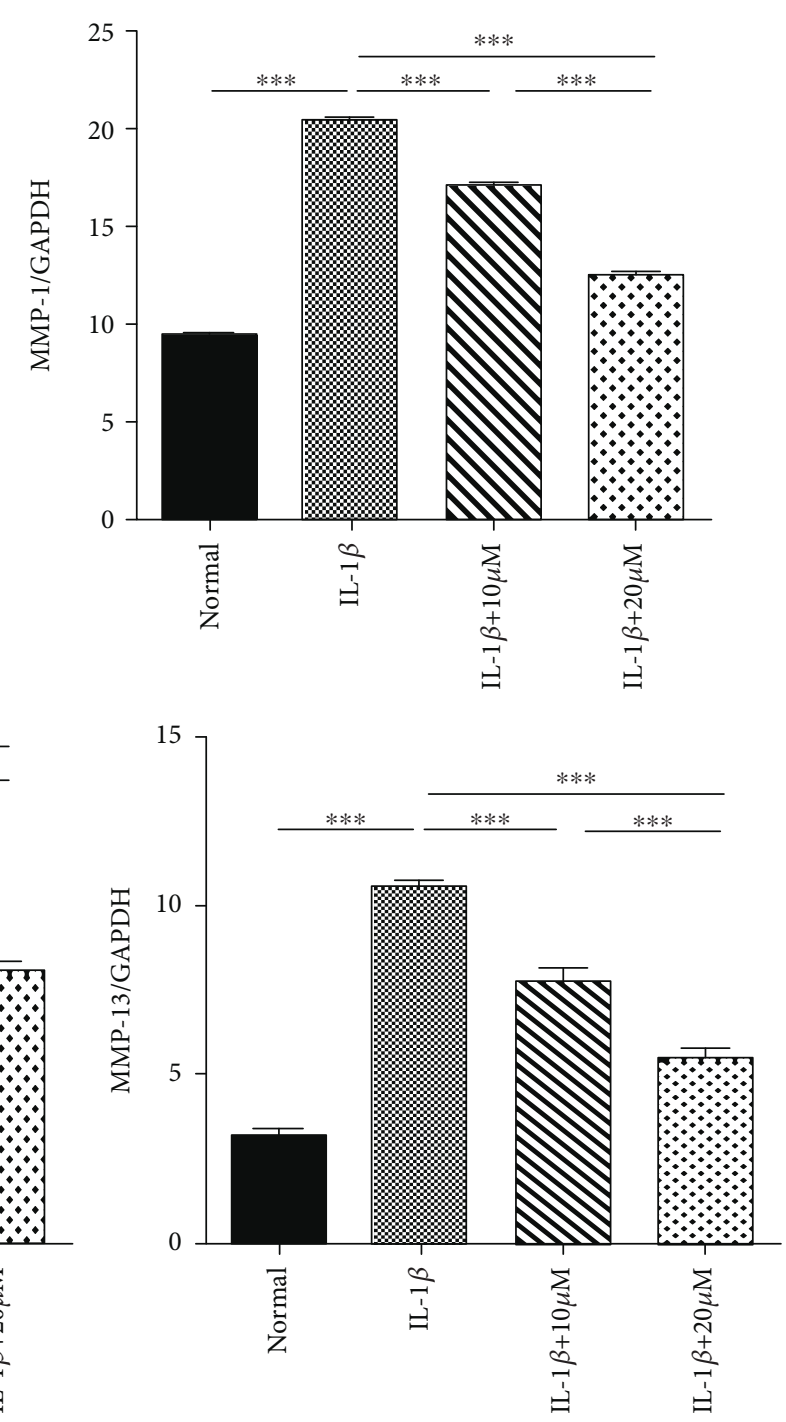

(b)

FIGURE 3: Effects of tricetin on the expression of matrix metalloproteinase- (MMP-) 1, MMP-3, and MMP-13, as determined by real-time PCR (RT-PCR) (a) and western blot (b). Chondrocytes pretreated with 10 or $20 \mu \mathrm{M}$ tricetin for $3 \mathrm{~h}$ were cultured with interleukin- (IL-) $1 \beta(10 \mathrm{ng} / \mathrm{ml})$ for $24 \mathrm{~h}$. Each column represents the mean \pm SD from triplicate samples in three independent experiments. IL-1 $\beta$ (10 $\mathrm{ng} / \mathrm{ml}$ ) alone significantly increased MMP-1, MMP-3, and MMP-13 expression compared to the untreated group $(p<0.05)$. Tricetin $(10$ or $20 \mu \mathrm{M})$ decreased IL- $1 \beta$-induced MMP production. ${ }^{* * *} p<0.001$ and ${ }^{* *} p<0.01$; NS: not significant. 


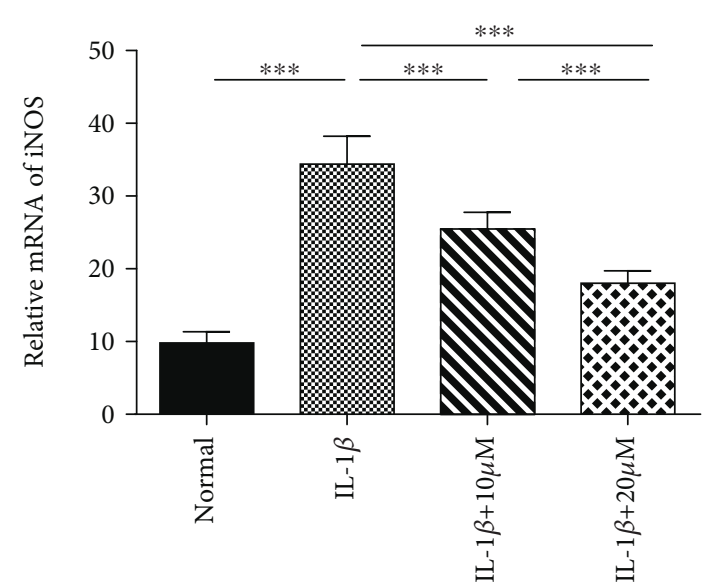

(a)

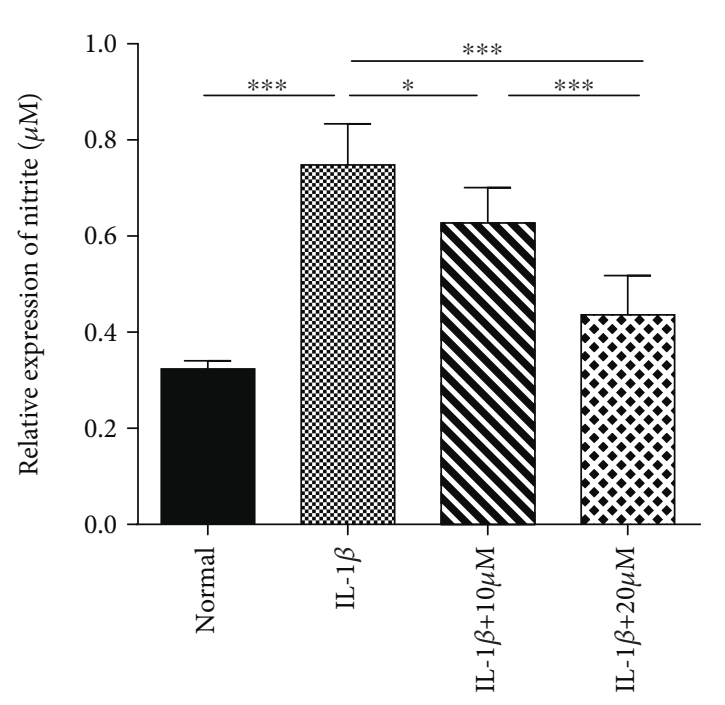

(c)

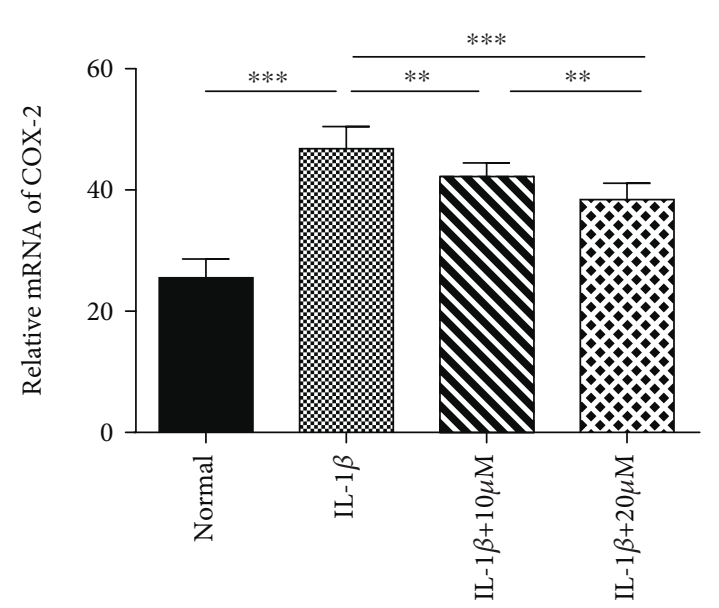

(b)

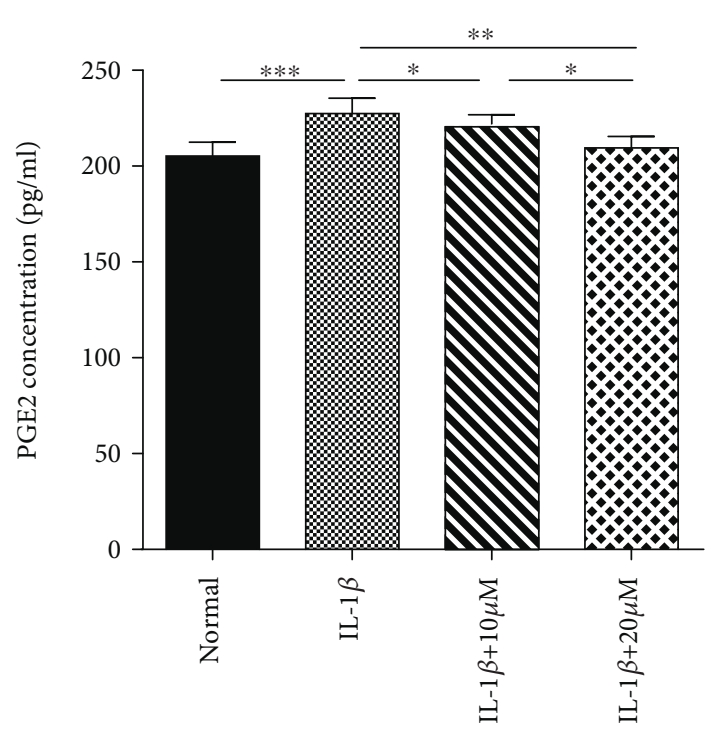

(d)

FIGURE 4: Effects of tricetin on nitric oxide (NO) and prostaglandin E2 (PGE2) production in IL- $1 \beta$-induced chondrocytes, as determined by RT-PCR ( $a$ and b), the Griess reaction (c), and ELISA (d). Each column represents the mean \pm SD from triplicate samples in three independent experiments. Tricetin $(10$ and $20 \mu \mathrm{M})$ significantly inhibited both IL- $1 \beta$-induced inducible NO synthase (iNOS) gene expression and NO production, as well as cyclooygenase 2 (COX-2) and PGE2 expression. ${ }^{* * *} p<0.001,{ }^{* *} p<0.01$, and ${ }^{*} p<0.05$.

all analyses, a $p$ value $<0.05$ was considered to indicate statistical significance.

\section{Results}

3.1. Effects of Tricetin on Cell Viability. As shown in Figure 2, tricetin at a concentration of $0-20 \mu \mathrm{M}$ exhibited no significant cytotoxicity to the cultured chondrocytes. Higher concentrations of tricetin $(40$ and $80 \mu \mathrm{M})$ inhibited chondrocyte proliferation compared to nontreated cells. Therefore, 10 and 20 $\mu \mathrm{M}$ concentrations of tricetin were viewed as safe concentrations and used in the following experiments.

3.2. Effects of Tricetin on $M M P-1, M M P-3$, and $M M P-13$ Expression in Chondrocytes. The effect of tricetin on MMP1, MMP-3, and MMP-13 mRNA expression was assessed using RT-PCR (Figure 3(a)). The results showed that IL- $1 \beta$ $(10 \mathrm{ng} / \mathrm{ml})$ significantly increased the expression of all three enzymes compared to the untreated control group, in accordance with the previous report [19]. The anticatabolic effect of tricetin at different concentrations was evidenced by its reduction of IL- $1 \beta$-induced MMP expression. On the western blot (Figure 3(b)), the changes in MMP-1, MMP-3, and MMP-13 protein expression were similar among the four groups, consistent with the quantitative RT-PCR results.

3.3. Effects of Tricetin on NO and PGE2 Production. The antiinflammatory effects of tricetin were also evaluated, by measuring NO and PGE2 expression in the rat chondrocytes. According to the results of the Griess reaction and RT-PCR (Figure 4), stimulation with IL-1 $\beta(10 \mathrm{ng} / \mathrm{ml})$ for $24 \mathrm{~h}$ led to a significant increase in both iNOS gene expression and NO production compared to the untreated group. Tricetin, at a concentration of either 10 or $20 \mu \mathrm{M}$, decreased the IL$1 \beta$-induced expression of the iNOS gene and the production 
of NO, as well as COX-2 gene expression and PGE2 production in chondrocytes.

3.4. Tricetin Inhibits IL-1 $\beta$-Induced Apoptosis by Suppressing Caspase-3 Activity. Caspase-3 activity increased significantly following the addition of IL- $1 \beta$, whereas in chondrocytes treated with tricetin a marked and dose-dependent decrease was observed (Figure 5).

3.5. Tricetin Suppresses the Apoptotic Pathway Mediated by $B c l-2$ and Bax. Both qRT-PCR (Figure 6(a)) and western blot (Figure 6(b)) analyses showed that IL-1 $\beta$ stimulation alone significantly increased the level of the proapoptotic factor Bax, whereas the expression of the antiapoptotic factor Bcl2 was decreased. However, pretreatment of the chondrocytes with tricetin increased the transcript and protein levels of Bcl-2 and decreased those of $\operatorname{Bax}(p<0.05)$.

3.6. Effects of Tricetin on MAPK Activation in Chondrocytes. To determine the potential mechanism underlying the effect of tricetin in IL- $1 \beta$-stimulated chondrocytes, alterations in the MAPK pathway were assessed. Compared to the control group, the levels of $\mathrm{p}-J \mathrm{NK}, \mathrm{p}$-ERK, and p-p38 were markedly increased in the group treated with IL-1 $\beta$ alone (Figure 7). Treatment with tricetin $(10$ and $20 \mu \mathrm{M})$ significantly attenuated the IL- $1 \beta$-induced phosphorylation of $\mathrm{p}$-JNK and $\mathrm{p}$ $\mathrm{p} 38$, but not that of $\mathrm{p}$-ERK. In addition, the total basal levels of JNK, p38, and ERK were unaffected by IL- $1 \beta$ and tricetin.

\section{Discussion}

Tricetin shows a wide range of pharmacological activities in several disease states, especially cancer and inflammation. Its anti-inflammatory activity in lipopolysaccharide- (LPS-) exposed kidney mesangial cells is mediated by its ability to decrease LPS-induced NO production [18]. Chang et al. found that tricetin inhibits MMP-9 expression in human osteosarcoma cells via the MAPK signaling pathway [17]. The inhibition of MMP expression has also been implicated in the antimetastatic properties of tricetin in human glioblastoma multiforme and oral cancer cells [20,21]. These studies clearly demonstrated the strong correlation between tricetin and MMP expression. Since an increase in MMP levels is regarded as a risk factor for the erosion of the articular cartilage, in this study, we investigated the underlying effect of tricetin in chondrocytes. To the best of our knowledge, this study is the first to show that tricetin prevents IL- $1 \beta$-induced catabolism and inflammation in chondrocytes. Moreover, an antiapoptotic role for tricetin, by regulating the Bax/Bcl-2 pathway, was also determined. This chondroprotective effect of tricetin was then linked to the MAPK signaling pathway.

In the pathological process of OA, ECM degradation, mediated by MMPs, ADAMTS, and cathepsins [22-24], plays a fundamental role. MMPs are a calcium-dependent family of catabolic enzymes responsible for cartilage degradation; they can be divided into three groups: collagenases, gelatinases, and stromelysin. Type II collagen, which together with aggrecan is the main component of the cartilage matrix, is cleaved predominantly by MMP-13 and MMP-3 and

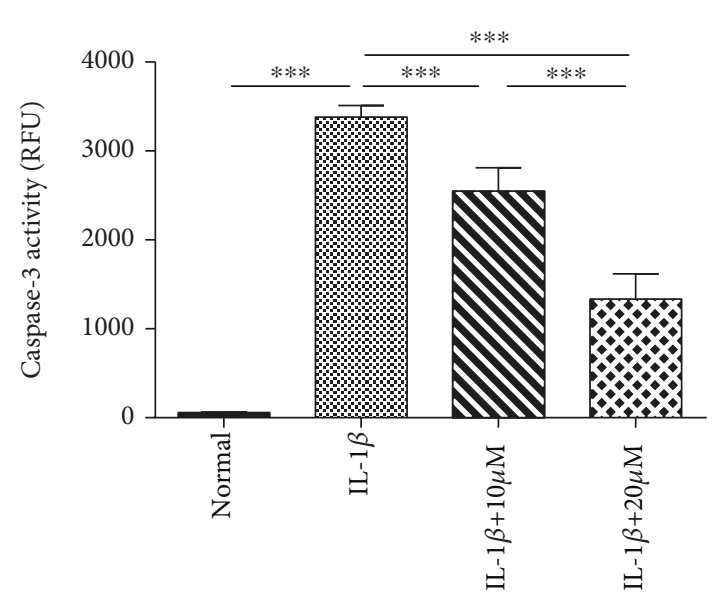

FIgURe 5: Effects of tricetin on caspase-3 activity. In the absence of tricetin, caspase- 3 activity is significantly increased in IL- $1 \beta$ stimulated chondrocytes $(p<0.05)$. Tricetin $(10$ and $20 \mu \mathrm{M})$ downregulates IL- $1 \beta$-induced caspase- 3 activity. Each column represents the mean \pm SD from triplicate samples in three independent experiments. ${ }^{* * *} p<0.001$.

aggrecan by ADAMTS [25]. These catabolic mediators are therefore potential therapeutic targets. In MMP-13 knockout mice, reductions in tibial cartilage damage and aggrecan loss compared to wild-type mice were observed [26]. Based on these findings, we explored the anticatabolic effect of tricetin by measuring the levels of MMP-1, MMP-3, and MMP-13 in chondrocytes pretreated with IL- $1 \beta$ to simulate the inflammatory environment. IL- $1 \beta$ was a classical proinflammatory cytokine and widely used to simulate the production of MMPs and other inflammatory mediators in chondrocytes [27]. According to the previous study, IL- $1 \beta$ at a concentration of $10 \mathrm{ng} / \mathrm{ml}$ has been well accepted to mimic pathological events of OA [28]. As expected, IL- $1 \beta(10 \mathrm{ng} / \mathrm{ml})$ significantly increased the expression of catabolic, inflammatory, and apoptotic factors in the treated cells, consistent with the results of the previous study [29]. However, in IL-1 $\beta$ induced and tricetin-treated chondrocytes, MMPs were downregulated, as was the expression of the genes encoding iNOS and COX-2. Thus, the chondroprotective effect of tricetin seems to be due to its regulation of the expression of catabolic and inflammatory factors. The recent studies have also demonstrated that many members of the flavanoid family, such as anthocyanins, wogonin, and icariin, decrease catabolic marker genes and reduce extracellular matrix breakdown [30-32]. These data suggested that flavonoid administration could ameliorate the progress of $\mathrm{OA}$ and may be a potential therapeutic strategy for OA treatment. The dysregulation of apoptosis contributes to the development of OA. The previous study has reported that chondrocyte apoptosis and a decrease in chondrocyte survival signals were associated with the catabolic process of OA [33]. The caspase family is regarded as the key regulator of apoptosis. Caspase- 3 is a key enzyme in the activation of the mitochondrial-dependent apoptosis pathway [34], and its expression is significantly increased in OA cartilage in the knee and hip compared to control tissues [35]. The 

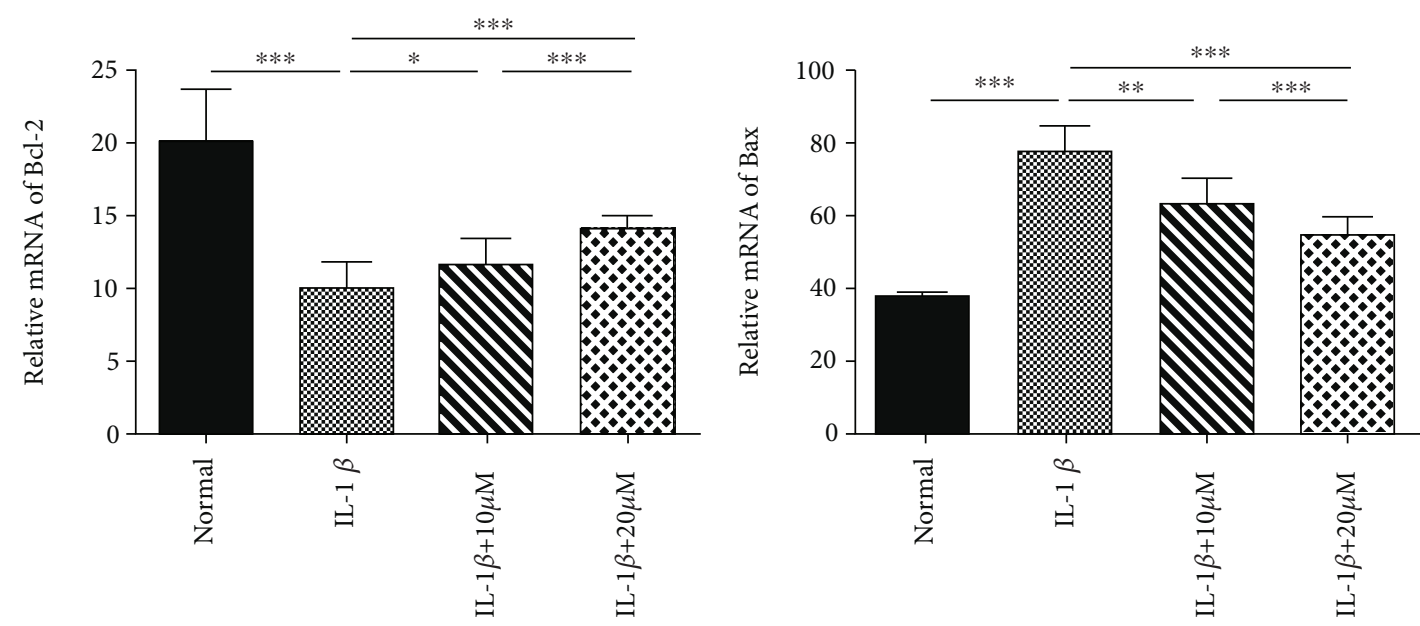

(a)
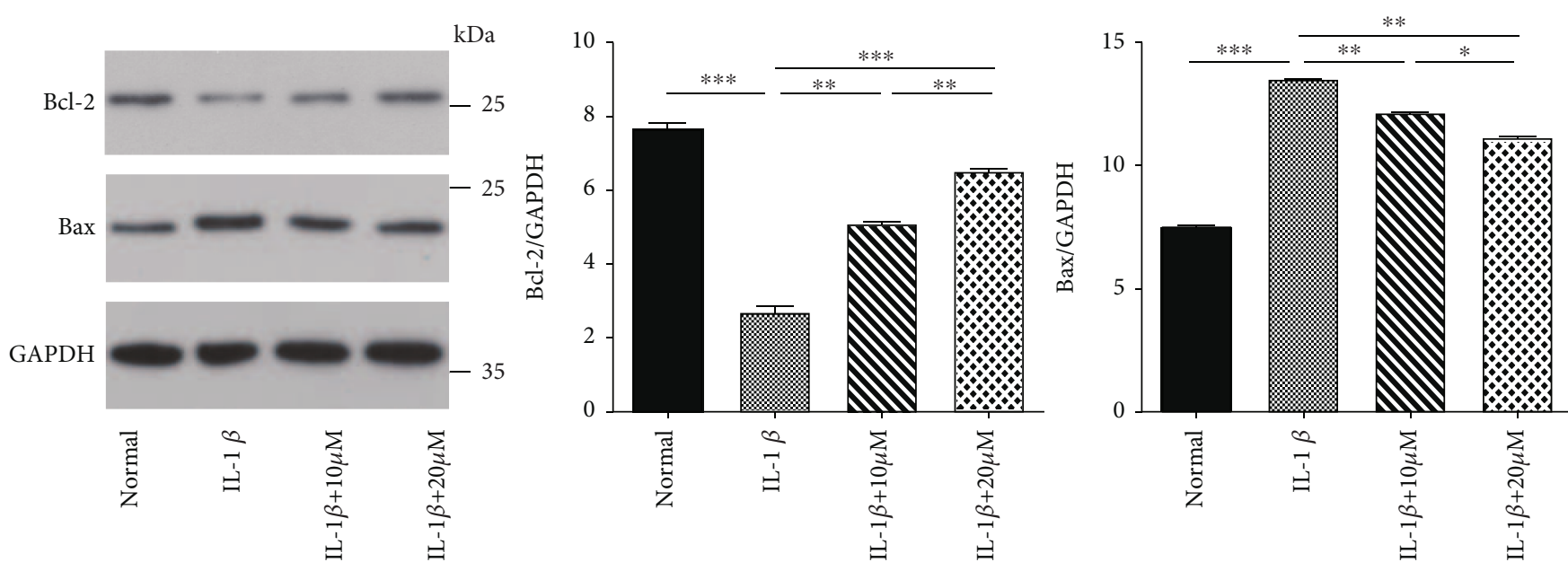

(b)

FIGURE 6: Effects of tricetin on Bcl-2 and Bax gene and protein expression, as determined by RT-PCR (a) and western blot (b). After the stimulation of rat chondrocytes with IL- $1 \beta$ alone, Bax gene and protein levels increased significantly, while Bcl-2 expression decreased. Tricetin significantly decreased Bax production and increased Bcl-2 expression in IL- $\beta$-induced rat chondrocytes. Each column represents the mean \pm SD from triplicate samples in three independent experiments. ${ }^{* * *} p<0.001,{ }^{* *} p<0.01$, and ${ }^{*} p<0.05$.

Bcl family is divided into proapoptotic (Bax and the BH3only families) and antiapoptotic (Bcl-2, Bcl-xL, Bcl-w, A1, and Mcl1) mediators. Decreased Bcl-2 levels were demonstrated in damage OA articular cartilage compared to nonlesional areas of the same tissue [36]. Similarly, chondrocytes incubated with the proapoptotic factors TNF- $\alpha$, IL- $1 \beta$, and interferon- $\gamma$ had a higher Bax/Bcl-2 ratio [37]. Chondrocyte stimulation with IL-1 $\beta$ was shown to activate caspase- 3 and upregulate Bax [38]. In this study, apoptosis and the antiapoptotic effect of tricetin were investigated in chondrocytes by measuring Bcl-2 and Bax levels. Pretreatment with tricetin was shown to directly increase the transcript and protein levels of Bcl-2 and decrease those of Bax. Taken together, our findings provide evidence that tricetin regulates the $\mathrm{Bax} / \mathrm{Bcl}-2 / \mathrm{caspase}-3$ pathway and thereby inhibits the apoptosis of IL- $1 \beta$-stimulated chondrocytes.

The MAPK cascade involves a highly conserved family of serine/threonine protein kinases. The MAPK signaling pathway, which includes ERK1/2, Jnk, and p38, plays a central role in chondrocyte proliferation, apoptosis, and survival $[39,40]$. In our in vitro study, we demonstrated that tricetin inhibits the phosphorylation of ERK and p38, consistent with its ability to reduce Akt and p38 phosphorylation in human osteosarcoma cells [17]. Chung et al. reported that tricetin decreases MMP activity by downregulating p38 and JNK [20]. These results suggest that tricetin acts as a ligand that binds to an upstream factor in the MAPK signaling pathway. However, the direct target of tricetin in chondrocytes remains to be identified. A limitation of our study is that our current research has not carried out any experiment of MAPK pathway silencing to prove that MAPK is fully involved in IL-1 $\beta$-induced inflammation and apoptosis with tricetin treatment. It needs a further study to certify that the MAPK signaling pathway is the main mechanism in which tricetin protects rat chondrocytes against IL- $1 \beta$-induced inflammation and apoptosis. 

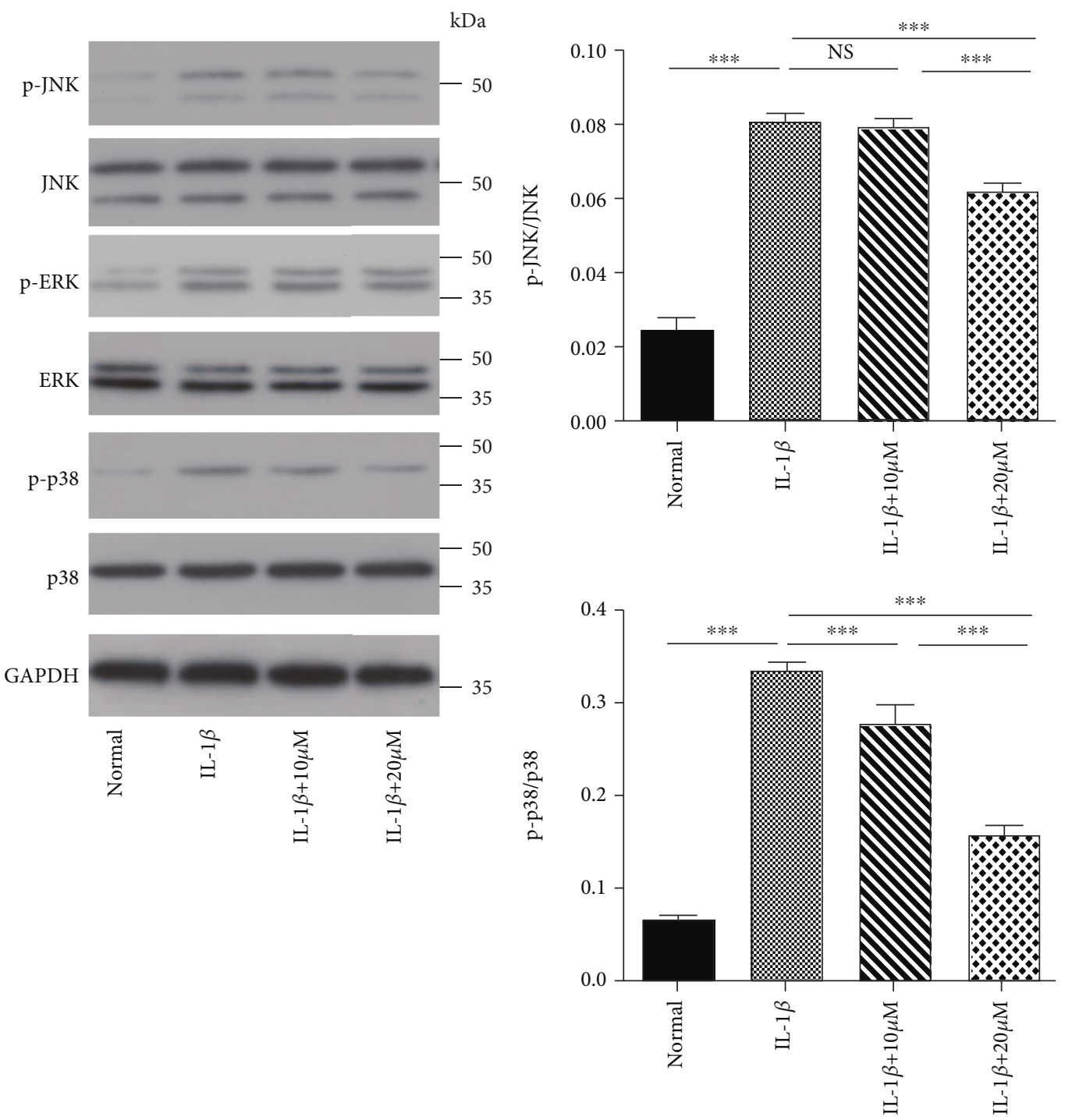

(a)

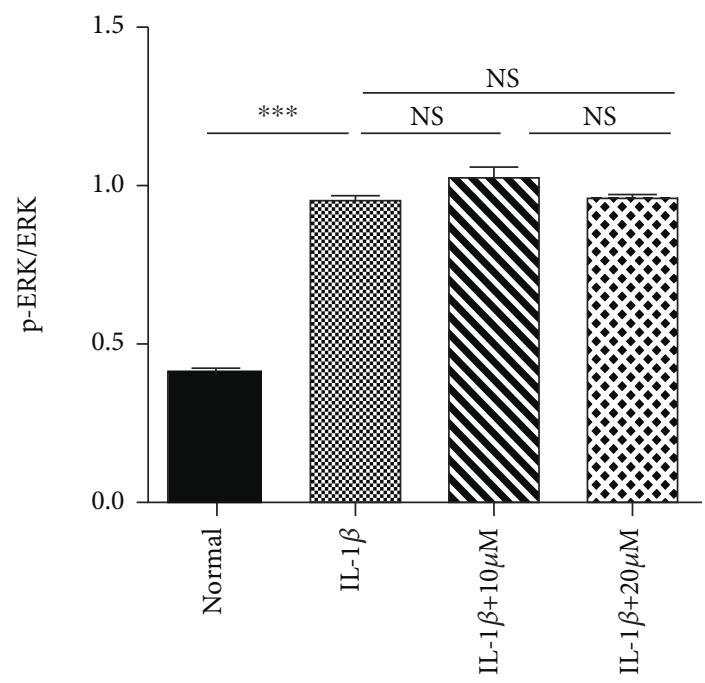

(b)

Figure 7: Effects of tricetin on MAPK activation in IL- $1 \beta$-induced chondrocytes. Tricetin decreased p-JNK and p-p38 protein levels, but not the level of p-ERK in IL- $1 \beta$-induced chondrocytes. GAPDH was used as the loading control in western blotting. Each column represents the mean \pm SD from triplicate samples in three independent experiments. ${ }^{* * *} p<0.001$, NS: not significant, and ${ }^{*} p<0.05$ vs. the IL- $1 \beta$ group. ${ }^{\#} p<0.05$ vs. the control group. 


\section{Conclusion}

Our study showed that tricetin decreases the expression of MMP-1, MMP-3, and MMP-13, at both the gene and protein level, in IL- $1 \beta$-induced rat chondrocytes. Tricetin also inhibited IL- $1 \beta$-induced NO and PGE2 production by modulating iNOS and COX-2 gene expression, as well as apoptosis by regulating the $\mathrm{Bax} / \mathrm{Bcl}-2 /$ caspase- 3 pathway. The chondroprotective effect of tricetin might be attributed to its suppression of the MAPK signaling pathway. Thus, tricetin should be explored as the basis for a new approach to the treatment of OA.

\section{Data Availability}

The data used to support the findings of this study are included within the article.

\section{Conflicts of Interest}

The authors declare that there is no conflict of interest regarding the publication of this paper.

\section{Authors' Contributions}

Fang-Fang Sun and Peng-Fei $\mathrm{Hu}$ contributed equally to this study.

\section{Acknowledgments}

This study was supported by the National Natural Science Foundation of China (grant no. 81301584).

\section{References}

[1] D. J. Hunter and D. T. Felson, "Osteoarthritis," BMJ, vol. 332, no. 7542, pp. 639-642, 2006.

[2] R. Liu-Bryan and R. Terkeltaub, "Emerging regulators of the inflammatory process in osteoarthritis," Nature Reviews Rheumatology, vol. 11, no. 1, pp. 35-44, 2015.

[3] H. S. Hwang and H. A. Kim, "Chondrocyte apoptosis in the pathogenesis of osteoarthritis," International Journal of Molecular Sciences, vol. 16, no. 11, pp. 26035-26054, 2015.

[4] D. J. Blasioli and D. L. Kaplan, "The roles of catabolic factors in the development of osteoarthritis," Tissue Engineering Part B: Reviews, vol. 20, no. 4, pp. 355-363, 2014.

[5] P. S. Burrage, K. S. Mix, and C. E. Brinckerhoff, "Matrix metalloproteinases: role in arthritis," Frontiers in Bioscience, vol. 11, no. 1, pp. 529-543, 2006.

[6] F. Heraud, A. Heraud, and M. F. Harmand, "Apoptosis in normal and osteoarthritic human articular cartilage," Annals of the Rheumatic Diseases, vol. 59, no. 12, pp. 959-965, 2000.

[7] C. M. Thomas, C. J. Fuller, C. E. Whittles, and M. Sharif, "Chondrocyte death by apoptosis is associated with cartilage matrix degradation," Osteoarthritis and Cartilage, vol. 15, no. 1, pp. 27-34, 2007.

[8] S. Kumar and A. K. Pandey, "Chemistry and biological activities of flavonoids: an overview," The Scientific World Journal, vol. 2013, Article ID 162750, 16 pages, 2013.

[9] S. Venturelli, M. Burkard, M. Biendl, U. M. Lauer, J. Frank, and C. Busch, "Prenylated chalcones and flavonoids for the prevention and treatment of cancer," Nutrition, vol. 32, no. 11-12, pp. 1171-1178, 2016.

[10] J. Wu, K. Liu, and X. Shi, "The anti-inflammatory activity of several flavonoids isolated from Murraya paniculata on murine macrophage cell line and gastric epithelial cell (GES1)," Pharmaceutical Biology, vol. 54, no. 5, pp. 868-881, 2016.

[11] N. Gottstein, B. A. Ewins, C. Eccleston et al., "Effect of genistein and daidzein on platelet aggregation and monocyte and endothelial function," British Journal of Nutrition, vol. 89, no. 05, pp. 607-616, 2003.

[12] D. I. Al-Dosary, A. S. Alhomida, and M. S. Ola, "Protective effects of dietary flavonoids in diabetic induced retinal neurodegeneration," Current Drug Targets, vol. 18, no. 13, pp. 14681476, 2017.

[13] Z. Yuan, G. Luan, Z. Wang et al., "Flavonoids from Potentilla parvifolia Fisch and Their Neuroprotective Effects in Human Neuroblastoma SH-SY 5Y Cells in vitro," Chemistry \& biodiversity, vol. 14, no. 6, 2017.

[14] W. P. Chen, Z. N. Hu, L. B. Jin, and L. D. Wu, "Licochalcone A inhibits MMPs and ADAMTSs via the NF- $\kappa$ B and Wnt/ $\beta$-catenin signaling pathways in rat chondrocytes," Cellular Physiology and Biochemistry, vol. 43, no. 3, pp. 937944, 2017.

[15] W. Zheng, Z. Feng, Y. Lou et al., "Silibinin protects against osteoarthritis through inhibiting the inflammatory response and cartilage matrix degradation in vitro and in vivo," Oncotarget, vol. 8, no. 59, pp. 99649-99665, 2017.

[16] M. G. Campos, R. F. Webby, and K. R. Markham, "The unique occurrence of the flavone aglycone tricetin in Myrtaceae pollen," Zeitschrift für Naturforschung C, vol. 57, no. 9-10, pp. 944-946, 2002.

[17] P. Y. Chang, M. J. Hsieh, Y. S. Hsieh et al., "Tricetin inhibits human osteosarcoma cells metastasis by transcriptionally repressing MMP-9 via p38 and Akt pathways," Environmental Toxicology, vol. 32, no. 8, pp. 2032-2040, 2017.

[18] X. Wang, Z. Wang, P. S. Sidhu, U. R. Desai, and Q. Zhou, "6-Hydroxyflavone and derivatives exhibit potent antiinflammatory activity among mono-, di- and polyhydroxylated flavones in kidney mesangial cells," PLoS One, vol. 10, no. 3, article e0116409, 2015.

[19] Y. Mu, W. Hao, and S. Li, "Casticin protects against IL- $1 \beta$ induced inflammation in human osteoarthritis chondrocytes," European Journal of Pharmacology, vol. 842, pp. 314-320, 2018.

[20] T. T. Chung, C. Y. Chuang, Y. H. Teng et al., "Tricetin suppresses human oral cancer cell migration by reducing matrix metalloproteinase-9 expression through the mitogenactivated protein kinase signaling pathway," Environmental Toxicology, vol. 32, no. 11, pp. 2392-2399, 2017.

[21] R. Chao, J. M. Chow, Y. H. Hsieh et al., "Tricetin suppresses the migration/invasion of human glioblastoma multiforme cells by inhibiting matrix metalloproteinase- 2 through modulation of the expression and transcriptional activity of specificity protein 1," Expert Opinion on Therapeutic Targets, vol. 19, no. 10, pp. 1293-1306, 2015.

[22] A. Okada and Y. Okada, "Progress of research in osteoarthritis. Metalloproteinases in osteoarthritis," Clinical Calcium, vol. 19, no. 11, pp. 1593-1601, 2009.

[23] P. Verma and K. Dalal, "ADAMTS-4 and ADAMTS-5: key enzymes in osteoarthritis," Journal of Cellular Biochemistry, vol. 112, no. 12, pp. 3507-3514, 2011. 
[24] Y. Yasuda, J. Kaleta, and D. Bromme, "The role of cathepsins in osteoporosis and arthritis: rationale for the design of new therapeutics," Advanced Drug Delivery Reviews, vol. 57, no. 7, pp. 973-993, 2005.

[25] H. Stanton, F. M. Rogerson, C. J. East et al., "ADAMTS5 is the major aggrecanase in mouse cartilage in vivo and in vitro," Nature, vol. 434, no. 7033, pp. 648-652, 2005.

[26] C. B. Little, A. Barai, D. Burkhardt et al., "Matrix metalloproteinase 13-deficient mice are resistant to osteoarthritic cartilage erosion but not chondrocyte hypertrophy or osteophyte development," Arthritis \& Rheumatism, vol. 60, no. 12, pp. 3723-3733, 2009.

[27] J. C. Fernandes, J. Martel-Pelletier, and J. P. Pelletier, "The role of cytokines in osteoarthritis pathophysiology," Biorheology, vol. 39, no. 1-2, pp. 237-246, 2002.

[28] P. Wang, Z. Mao, Q. Pan et al., "Histone deacetylase-4 and histone deacetylase- 8 regulate interleukin- $1 \beta$-induced cartilage catabolic degradation through MAPK/JNK and ERK pathways," International Journal of Molecular Medicine, vol. 41, pp. 2117-2127, 2018.

[29] K. Zhou, L. Hu, W. Liao, D. Yin, and F. Rui, "Coptisine prevented IL- $\beta$-induced expression of inflammatory mediators in chondrocytes," Inflammation, vol. 39, no. 4, pp. 1558-1565, 2016.

[30] T. Wongwichai, P. Teeyakasem, D. Pruksakorn, P. Kongtawelert, and P. Pothacharoen, "Anthocyanins and metabolites from purple rice inhibit IL- $1 \beta$-induced matrix metalloproteinases expression in human articular chondrocytes through the NF- $\kappa \mathrm{B}$ and ERK/MAPK pathway," Biomedicine \& Pharmacotherapy, vol. 112, article 108610, 2019.

[31] P. Wang, F. Zhang, Q. He et al., "Flavonoid compound icariin activates hypoxia inducible factor- $1 \alpha$ in chondrocytes and promotes articular cartilage repair," PLoS One, vol. 11, no. 2, article e0148372, 2016.

[32] N. M. Khan, A. Haseeb, M. Y. Ansari, and T. M. Haqqi, "A wogonin-rich-fraction of Scutellaria baicalensis root extract exerts chondroprotective effects by suppressing IL- $1 \beta$-induced activation of AP-1 in human OA chondrocytes," Scientific Reports, vol. 7, no. 1, article 43789, 2017.

[33] R. Goggs, S. D. Carter, G. Schulze-Tanzil, M. Shakibaei, and A. Mobasheri, "Apoptosis and the loss of chondrocyte survival signals contribute to articular cartilage degradation in osteoarthritis," The Veterinary Journal, vol. 166, no. 2, pp. 140-158, 2003.

[34] D. W. Nicholson and N. A. Thornberry, "Caspases: killer proteases," Trends in Biochemical Sciences, vol. 22, no. 8, pp. 299-306, 1997.

[35] M. Sharif, A. Whitehouse, P. Sharman, M. Perry, and M. Adams, "Increased apoptosis in human osteoarthritic cartilage corresponds to reduced cell density and expression of caspase-3," Arthritis \& Rheumatism, vol. 50, no. 2, pp. 507$515,2004$.

[36] H. A. Kim, Y. J. Lee, S. C. Seong, K. W. Choe, and Y. W. Song, "Apoptotic chondrocyte death in human osteoarthritis," The Journal of rheumatology, vol. 27, no. 2, pp. 455-462, 2000.

[37] N. Adán, J. Guzmán-Morales, M. G. Ledesma-Colunga et al., "Prolactin promotes cartilage survival and attenuates inflammation in inflammatory arthritis," The Journal of Clinical Investigation, vol. 123, no. 9, pp. 3902-3913, 2013.

[38] X. Zhang, X. Xu, T. Xu, and S. Qin, “ $\beta$-Ecdysterone suppresses interleukin- $1 \beta$-induced apoptosis and inflammation in rat chondrocytes via inhibition of NF- $\kappa$ B signaling pathway," Drug Development Research, vol. 75, pp. 195-201, 2014.

[39] S. Hayashi, T. Nishiyama, Y. Miura et al., "DcR3 induces cell proliferation through MAPK signaling in chondrocytes of osteoarthritis," Osteoarthritis and Cartilage, vol. 19, no. 7, pp. 903-910, 2011.

[40] Q. Ge, H. Wang, X. Xu, L. Xu, L. Zhai, and R. Tao, "PDK1 promotes apoptosis of chondrocytes via modulating MAPK pathway in osteoarthritis," Tissue Cell, vol. 49, no. 6, pp. 719-725, 2017. 


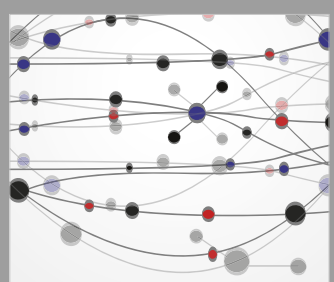

The Scientific World Journal
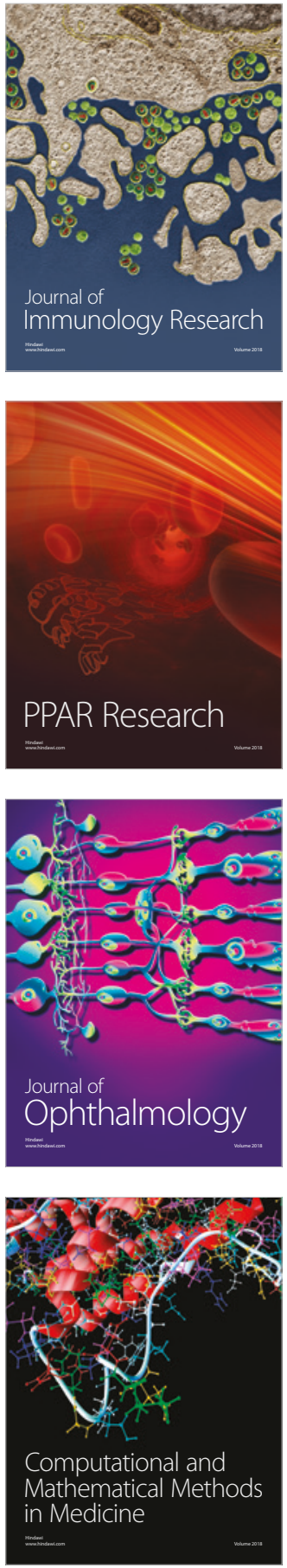

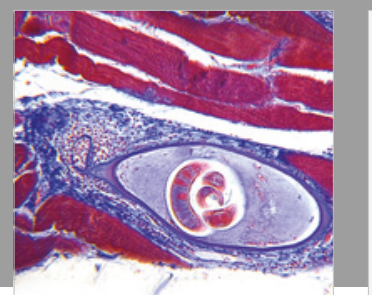

Gastroenterology Research and Practice

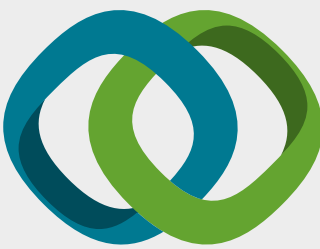

\section{Hindawi}

Submit your manuscripts at

www.hindawi.com
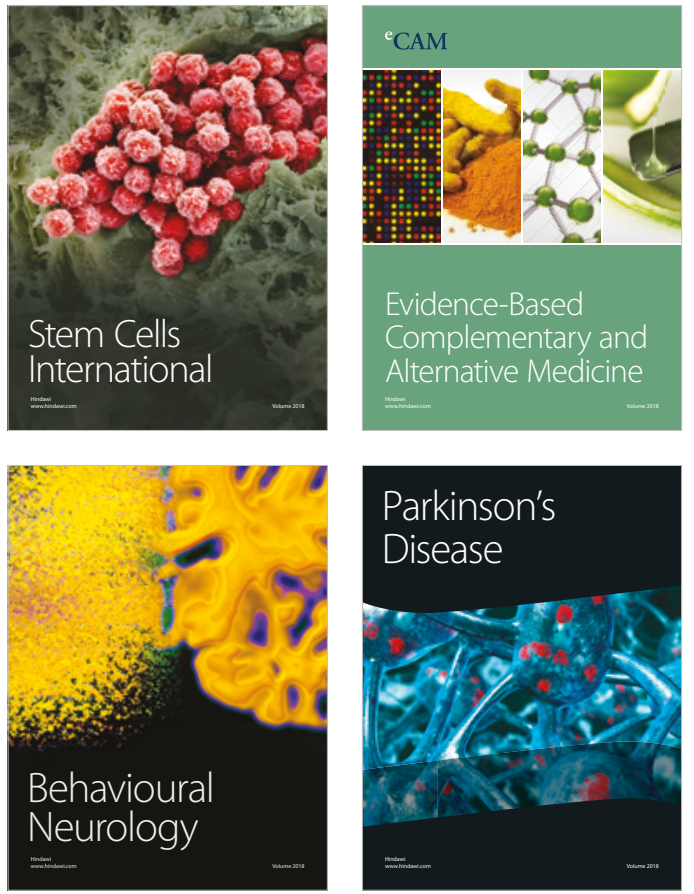

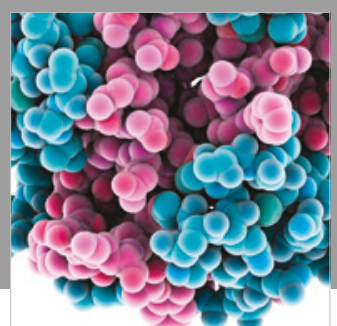

ournal of

Diabetes Research

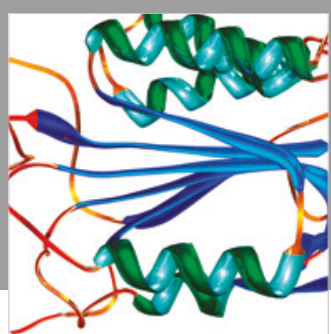

Disease Markers
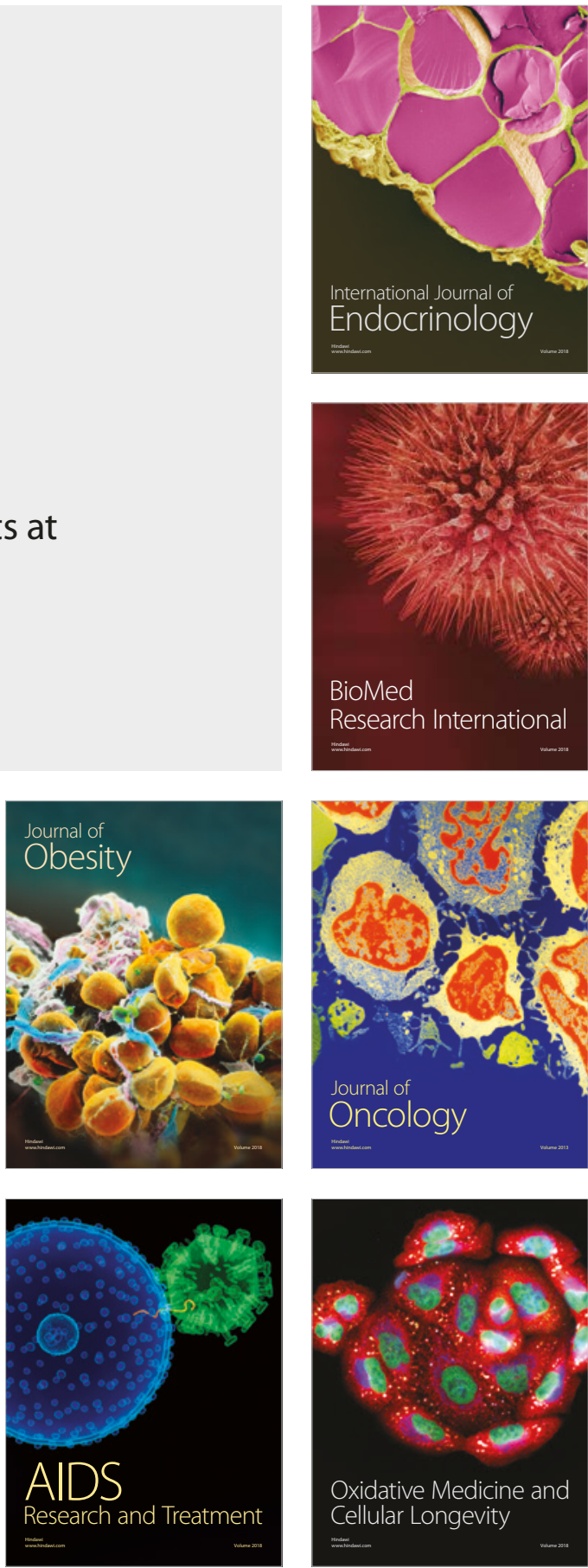